\title{
Two Principles of Cultivating Young Marxists Among College Students
}

\author{
Jie $\mathrm{Gao}^{1}$ \\ ${ }^{1}$ School of Marxism, Central University of Finance and Economics, Beijing, China \\ Correspondence: Jie Gao. E-mail: 2015110121@email.cufe.edu.cn
}

Received: October 12, 2020

Accepted: October 25, $2020 \quad$ Online Published: October 31, 2020

doi:10.5539/ass.v16n11p136

URL: https://doi.org/10.5539/ass.v16n11p136

\begin{abstract}
The principle of cultivating young Marxists among college students means that the training work follows the policies and guidelines established by the characteristics and growth laws of young Marxists among college students. The cultivation of young Marxists among college students should adhere to the following two principles: one is to focus on combining the need for stimulating belief with the rational choice of guiding belief; the other is to focus on combining dynamic selection and classified cultivation.
\end{abstract}

Keywords: China, college students, young Marxists, cultivation principles

\section{Introduction}

Young people are the most dynamic and creative group in society, and they are the social group leading the trend (Wan, 2016). The growth of young Marxists is inseparable from specific social and historical conditions, as well as the arduous ideological training and practical tests in the course of life struggle. Therefore, young college students' choice of Marxism as their lifelong belief and unremitting struggle for it cannot be achieved overnight, especially for contemporary youth groups. On the one hand, young people's own ideology is not yet mature; they are vulnerable to the impact of multicultural thoughts and the influence of complex and changeable social environment. On the other hand, the life experiences of youth groups, especially college students, generally lack the experience and test of social practice. Consequently, it is necessary to grasp the correct working principles and guidelines in the youth group, especially in the key training target group: young Marxists among college students.

\section{Follow the Law of Belief Generation and Cultivate Marxist Belief Personality}

Marxism is a theoretical system founded and developed by Marx and Engels. It is a theoretical form and an object of belief. Marxists are believers and practitioners of Marxist theory, a specific figure form, and also the main body of faith.

Marxists in college students have basically established their belief in Marxism, and their behaviors have begun to show their adherence to and practice of the belief in Marxism, which is their most essential distinguishing feature. Therefore, the training work of young Marxists among college students is the cultivation and strengthening of Marxist belief in the final analysis. It must follow the law of the generation and development of Marxist belief and the law of the growth of contemporary college students, and focus on guiding the trainees to gradually strengthen their belief cognition, stimulate their belief emotion and strengthen their belief will, and then gradually form and improve their own Marxist belief personality through the practice of Marxist belief.

\subsection{The Key Link in the Training Work Is to Guide the Generation and Strengthening of Beliefs}

\subsubsection{Belief in Marxism Is the Cornerstone of the Growth of Young Marxists}

Belief is people's unswerving trust and persistent pursuit of their core beliefs that they believe embodies the highest value of life. It is specifically manifested as the sincere belief and conscious pursuit of the belief object by the belief subject. People become the primate of all things because of faith (Liu, 2012). As a deep spiritual need of human beings, faith has a profound impact on people's life goals and life order, as well as on people's daily behavior and lifestyle.

Marxist belief refers to the belief subject's belief in and following the theoretical system, value goal, social ideal and fundamental purpose of Marxism, which is the core part of the spiritual world of Marxist belief subject. The 
belief in Marxism consists of four parts: the materialist world picture, the lofty ideal of communism, the fundamental purpose of serving the people and the free and comprehensive pursuit of life (Liu, 2013). Among them, the lofty ideal of communism and the fundamental purpose of serving the people are the two core elements. The former sets the goal of pursuing social ideals and values for Marxist beliefs, while the latter sets the fundamental beliefs and moral requirements for Marxist beliefs (Liu, 2013).

For contemporary college students, the generation of Marxist belief is a complicated and arduous process. On the one hand, college students are in their youth, which is also an important transitional stage in their life course. In this transitional growth stage from adulthood, their sense of autonomy and independence is increasing day by day, especially when their critical thinking ability and creative thinking ability are rapidly improved, they are also prone to self-centered psychological tendency. This feature makes them pay more attention to their own independent consciousness and value judgment in this period, and they are prone to reverse and extreme ideological tendencies, which will weaken their recognition of mainstream social ideas and even authoritative ideas to a great extent. As far as the training objects of young Marxists among college students are concerned, although they have excellent development potential that ordinary college students lack, they have the same cognitive and psychological characteristics as their peers in this growth stage, and their choice and continuous strengthening of Marxist beliefs will also be affected and restricted by many unfavorable factors.

On the other hand, as far as the object of Marxist belief is concerned, Marxist theory is a scientific system created and developed by its founders on the basis of critically inheriting the natural science, social science and thinking science of human society. At the same time, Marxist theory is a theoretical system which is highly abstracted and explained by its classical theoretical authors. To master this theoretical system, we must rise from an accurate understanding of the basic category of the huge volume of Marxism to a grasp of its theoretical integrity, which is a process with great cognitive difficulty. In other words, Marxist belief is limited to its recipients to a certain extent, and among college students, it is more "favored" for those outstanding college students who have excellent development potential and strong will to grow into Marxists.

The group characteristics of college students and the limitation of Marxist belief to their recipients determine that the process from choosing Marxist belief to believing in this belief is the key and difficult link in the growth process of young college students. From this perspective, the belief in Marxism can be regarded as the cornerstone of the growth of young Marxists among college students.

2.1.2 The Key Link of Training Work Is to Follow the Law of Belief Generation and Strengthen Belief Cultivation

People's belief is a dynamic construction process of spiritual consciousness structure, which takes belief in specific belief objects as the core and progresses step by step. It begins with a preliminary understanding of the "yes" or "no" of the belief object, and after a rational judgment of the belief object, it initially forms a belief consciousness of the belief object, and then produces a strong will and emotional identity, and finally reaches a state of completely affirming and accepting the belief object psychologically, that is, a state of belief.

The generation process of college students' belief in Marxism begins with their need and choice of belief in Marxism. After their psychological integration of belief cognition, belief emotion and belief will in their own belief mentality, they stimulate and produce the practice action of belief in Marxism, thus forming the belief personality of Marxism on the basis of organic unity of knowledge, emotion, meaning and practice, and then completing the generation and establishment of Marxist belief.

College stage is the key period for the generation and establishment of Marxist belief. The training objects in this growth stage will build up the framework of belief step by step on the basis of rational cognition, and gradually form and strengthen their own belief in practice. In the training of young Marxists among college students, we must firmly grasp the critical period of belief generation and the key link of Marxist belief education. On the basis of following the law of belief generation, we can effectively transmit Marx's theoretical system and its value principles to the training objects, stimulate them to confirm Marxism theory, experience emotion and practice belief, and finally promote them to form a perfect Marxist belief personality.

\subsection{The Focus of the Cultivation of Marxist Beliefs Is to Enhance the Belief Mentality of the Training Objects}

\subsubsection{Belief Mentality Is an Important Yardstick to Measure the Belief State of the Training Object}

Belief mentality is a kind of psychological and spiritual state of "believing" shown by the subject of belief. Without the subjective feeling of believers on the content of belief, there would be no existence of belief. Belief mentality consists of belief cognition, belief emotion and belief will. Among them, belief cognition is the premise of belief establishment, and the basic condition of belief is that believers have a certain degree of 
understanding the object of belief; Belief emotion is an active dynamic factor, and positive emotional experience can stimulate and promote belief cognition; Belief will is a stabilizing factor for belief mentality, which affirms a certain concept achieved by cognition, and makes it fixed and not easily changed. The interaction among belief cognition, belief emotion and belief will form a stable belief mentality, which is an important symbol to measure whether a person has become a belief subject or not, and also an important scale to measure the belief state of a belief subject.

In the belief mentality, belief cognition has a clear cognitive object, which is relatively easy to identify and cultivate. Belief emotion and belief will, as complex psychological elements, are deep in the spiritual world of the belief subject, and they will be influenced by the individual differences of the belief subject, so it is difficult to quantify and observe them. However, in the process of the formation and development of belief, belief emotion and belief will play a deeper and important role. As the choice of belief subject based on needs, the generation and maintenance of belief cannot be formed only by theoretical indoctrination from outside, but also by emotional acceptance and will maintenance of belief subject. For the work of cultivating young Marxists among college students, only by accurately grasping the belief mentality of the training object can we find out the belief state of the training object, that is, the standard and scale for measuring the degree of "true knowledge and true faith" of Marxism.

\subsubsection{Training Work Should Focus on Improving Belief Cognition, Stimulating Belief Emotion and Tempering} Belief Will

Belief cultivation is the key link in cultivating young Marxists among college students, and its focus lies in efforts to improve the mentality of Marxist belief of the trainees. Therefore, first of all, we should pay attention to guiding the training objects to improve their belief cognition of Marxism on the basis of accurately grasping the scientific truth and value of Marxist theory. The belief of young Marxists among college students is based on the scientific cognition of Marxist theory, which is the premise for them to improve their belief mentality and the basis for them to generate and maintain their Marxist belief. Only by fully understanding the historical development of Marxism, comprehending the world outlook and methodology of Marxism, and using these methods as ideological weapons to solve practical problems, can we gain theoretical recognition and emotional resonance of Marxism and consciously grow into the main body of Marxist belief. In addition, only on the premise of continuously improving their theoretical cognitive ability, can the trainees realize their conviction in the truth and value of Marxism, and find out the coincidence point between their own life achievements and the realization of human lofty ideals.

Secondly, we should pay attention to stimulating the belief emotion of the training objects. Emotional experience is an important link in the process of belief generation. There are two kinds of emotional factors in belief: emotions and feelings, in which emotion is shallow and short-lived, while feeling is deep and lasting. The deeper the belief, the deeper the feelings, and the greater the driving force, the more lasting it will be. It is worth noting that, unlike religious belief which overemphasizes emotional experience and leads to fanatical superstition, the scientific truth possessed by Marxism as a belief theory determines that the emotional experience of Marxist belief will be influenced and limited by rational thinking.

The emotional identity of the trainees to Marxism may sometimes be unconsciously produced under the influence and edification of the environment. Because the way of producing this belief emotion is unconscious, the subject of belief may not realize that he has formed an emotional identity with Marxism. Therefore, the training work should pay attention to the emotion formed by the training objects unconsciously, and continue to guide them to make correct value judgments and produce clear emotional experiences, so as to gradually produce deep recognition of Marxism in value and emotional dependence on faith. At the same time, some emotional identification with Marxism comes from the conscious and rational thinking of the believers. College students are in the shaping stage of their life. They are confident in their thinking and spontaneous in their behavior (Pu\&Yang, 2018). The limitations of this group in cognitive ability, especially in rational thinking ability, may make it difficult for them to have emotional identity at the belief level because they cannot grasp the whole theoretical picture of Marxism. Even the target group that has been strictly selected and has excellent development potential for the training of young Marxists among college students may encounter the same problems in the process of generating their beliefs. This requires that the training work should strengthen the training of the theoretical cognitive ability of the training objects, and guide them to match the truth and value of Marxism with their own spiritual needs for growth, so that Marxism can stimulate their own strong emotional identity in the process of meeting their main growth needs.

Thirdly, we should temper the belief will of Marxism. Belief will is the key to keep faith, and will factors make 
faith mentality tend to be stable, so as to avoid belief activities deviating from the original track and development direction. On the other hand, belief will is also the key factor for the transformation of cognitive and emotional elements in belief into practice, which can promote and motivate the belief subject to implement belief behavior. As far as the training work is concerned, facing the social environment in which numerous social thoughts and diverse values agitate each other, the training objects who are in the critical period of belief cultivation are likely to encounter certain difficulties and obstacles in the stage of maintaining Marxist belief and transforming behavior. Therefore, only by tempering and training the belief will of the objects can they stabilize the correct cognition and concept of Marxism formed by relying on belief cognition, and consciously resists the influence and erosion of wrong ideas on their belief cognition. Only by tempering the belief will of the training objects, can they always maintain strong and exclusive belief feelings for Marxist belief in their growth, and can they realize unswerving belief in and follow Marxism in their own life.

\subsection{The Formation of Marxist Belief Personality in the Practice of Faith}

\subsubsection{Belief Behavior Is the Guarantee of Forming Belief Personality}

The formation and establishment of belief requires not only the psychological integration of belief cognition, belief emotion and belief will of the belief subject, but also the verification and support of the belief subject relying on his own behavior pursuit and belief behavior, so that the belief subject can form a specific belief personality on the basis of organic unity of knowledge, emotion, will and behavior.

Belief behavior is the basic component of belief, and it is the symbol and embodiment of the transformation of belief mentality from subjective to objective. In the process of cultivating and shaping Marxist belief, only by transforming the belief elements in cognition, emotion and will of the training object into specific behavior pursuit and belief behavior can Marxist belief be truly established under the action of practical elements.

Belief behavior is also a process of self-verification of belief subjects. In the process of repeated comparison and test of belief practice, belief cognition is more accurate, belief emotion is more stable, and belief will be more firm. Therefore, in the process of belief education of Marxism, we must pay attention to guiding the training objects in the specific social scene, and repeatedly inspect, verify and strengthen their own beliefs based on the tempering of social practice. Only in this way can the trainees form an unshakable belief in Marxism on the basis of conscious practice.

\subsubsection{The Establishment of Belief Personality Is the Symbol of the Establishment of Marxist Belief}

Marxist belief refers to the belief subject's belief in and following the theoretical system, value goal, social ideal and fundamental purpose of Marxism, which is the core part of Marxist spiritual world. Different from general educational activities, Marxist belief education is a systematic integration of world outlook education, life outlook education and values education, which emphasizes the most fundamental guidance to people's spiritual life and soul. Secondly, the generation of Marxist belief emphasizes the stimulating and maintaining role of affective elements in belief mode and belief mentality, which highlights the important role and significance of shaping Marxist belief personality of the training object.

The belief personality of Marxism is realized on the basis of the unity of knowledge, emotion, meaning and practice, which is the thought and behavior paradigm consciously chosen and followed by the belief subject of Marxism. Once the belief subject of Marxism has formed the belief personality, the theoretical cognition, emotional experience and behavioral pursuit in its belief mode will be optimized and realized to the greatest extent in function. At this time, the potential and essential power of Marxist belief subject will be brought into full play and released to the greatest extent. On the other hand, the formation of Marxist belief personality not only emphasizes the rational cognition of the belief subject to Marxism, but also emphasizes that the belief subject should stimulate his belief emotion and tempers his persistent belief will in the realistic social scene and life picture. In this state, the subject of belief will deeply experience and perceive the sacredness and transcendence of Marxist belief in the practice of belief in real society, which sublimates the life value and significance of the subject of belief.

\section{Strengthen the Selection Process and Implement Classified Training}

In essence, human development is to establish human's dominant position in practice and give play to human's dominant role (Wan, 2016). As far as the cultivation of young Marxists for college students is concerned, when we judge whether a college student can be "willing to be" and "good at being" a young Marxist, there should be clear preconditions for affective elements and knowing and doing elements in his individual characteristics. In other words, a college student is more likely to grow into a young Marxist only if he has certain development potential. Therefore, the effective selection of training objects is the prerequisite for training work to achieve 
practical results. On the other hand, the training of young Marxists for college students should not only train Marxist theorists, but also focus on training young Marxists in professional fields in combination with the advantages and characteristics of talent training in colleges and universities. Therefore, the training work must start from the differences of the personality traits and ability structure of the training objects, and carry out individualized and classified training.

\subsection{Strengthen the Selection Process to Ensure the Quality of Training}

\subsubsection{Pay attention to Examining the Motivation of Participation and Accurately Selecting the Training Objects}

Motivation refers to arousing and maintaining the internal awakening state of individual's specific behavior, which is mainly manifested as individual's subjective desire and intention. It starts from individual's needs and has the function of stimulating, pointing, maintaining and coordinating human behavior. For the training work, the primary task is to accurately grasp the motivation behind the students' application to participate in the training of young Marxists and strive to become young Marxists among college students. In particular, we should pay attention to examining the relationship between their previous growth experiences and the motivation to apply for joining the training work, and strive to minimize the misjudgment of the candidates for the training work.

Individual motivation is generally influenced by family factors, educational factors and narrow sense socialization factors. Among them, family factors refer to the intergenerational mobility of family values, material living standards and lifestyles; Educational factors mainly refer to the individual's cultural level and the influence of public education on the cultivation of their values and moral norms; Socialization factors in a narrow sense refer to the mutual influence between specific groups and the mutual influence between individuals within groups. Therefore, apart from observing the cognitive state of Marx's theory and the typical behavior during school, we should also focus on the following observation points: First, we should examine the growth background of the candidates and judge the relationship between the formation of their participation motivation and the influence of family factors. Second, we should examine the relationship between the educational background of candidates and their Marxist belief needs and belief choices. Third, it is necessary to examine the relationship between the interpersonal communication state of the trainees and their personality traits and behavioral motives.

In addition, for the accurate selection of training objects, besides paying attention to examining the motivation factors of candidates, we should also grasp the following two factors. First of all, the training objects of the young Marxist training work of college students have specific potential characteristics, and students with these potential characteristics exist more among the backbone groups of students. In other words, the training objects with excellent development potential exist more among student cadres, student party members and backbone of student associations in student organizations at all levels. Secondly, the profound cognition and understanding of Marxist theoretical system is the prerequisite for the formation of Marxist belief. Therefore, in the selection work, the cognition of the candidates to the Marxist theory should be regarded as an important and quantifiable observation point, and on this basis, a variety of factors should be integrated to judge the growth potential of the candidates.

\subsubsection{Implement dynamic Selection of Training Objects}

The young Marxist of college students is a dynamic concept of development and tendency. Young Marxists among college students are growing Marxists, and they are outstanding college students who are striving to become a Marxist who has been tested by practice. To become a young Marxist, a college student must always have two basic conditions: "Marxist belief" and "excellent college student". The growth of young Marxists among college students is a dynamic development process. Therefore, the selection of training objects cannot be completed at one time, it must run through the whole training work, and the training objects should be dynamically eliminated and selected according to the periodic assessment.

The training of young Marxists among college students is different from professional teaching and daily ideological and political education. It can only be carried out for college students with specific development potential. However, due to the stage characteristics of college students' group growth, even students with excellent development potential may deviate from the training direction. In particular, the generation of Marxist belief, which is the core feature of young Marxists among college students, needs the effective connection and integration of the belief subject in three links: theoretical cognition, emotional confirmation and behavioral pursuit. However, in the process of individual belief generation, there may be obstacles and blocks in the connection and integration of various links, especially the lack of the maintaining role of the belief will elements in the belief mentality, which may lead to the difficulty in maintaining or even shaking the Marxist belief of the 
belief subject.

On the other hand, the young Marxist of college students should have the competency structure composed of specific cognitive elements, so the training work should be carried out aiming at the corresponding improvement of cognitive ability. However, the training of young Marxists among college students is carried out in the environment of professional talents training in colleges and universities, which means that the training of specific cognitive ability of young Marxists among college students is carried out at the same time as the professional study of the training objects, and this cumulative learning process has high requirements for the subjective initiative and ability accomplishment of the training objects. Therefore, in order to ensure the effectiveness of the training work, it is necessary to dynamically evaluate and judge the stage growth state and development potential of the training objects, and carefully eliminates the training objects without further development potential on this basis. To a certain extent, the training process of young Marxists among college students is the process of dynamically selecting the training objects on the basis of respecting the differences of the subject's will and personality.

\subsection{Follow the Principle of Teaching Students in Accordance with Their Aptitude to Implement Classified Training}

Training is to select outstanding students with special endowments and good development potential from college students, adopt an educational model different from other student groups, and help them grow into young Marxists. At the same time, the individual differences in the training target group also determine that the training work should be based on the individual characteristics of the training target and set up different training paths. Therefore, the training work must adhere to the principle of teaching students in accordance with their aptitude and carry out classified training.

\subsubsection{The Training Work Must Follow the Principle of Teaching Students in Accordance with Their Aptitude}

Individual problem is the starting point and destination of Marx's thought (Schaff, 2015). Cultivating young Marxists among college students must follow the principle of teaching students in accordance with their aptitude. Following this principle, the training work must take targeted training paths and methods according to the differences between affective factors and cognitive factors in the development potential of the training objects, and strive to meet the growth needs of the training objects on the basis of stimulating the initiative of the subjects.

"Personality" refers to the stable psychological characteristics formed during people's growth and life, also known as "personality psychological characteristics", which includes people's character, temperament and ability. People's personality differences are generally manifested in three aspects: personality, temperament and ability. Among them, the difference of human ability is mainly manifested in the difference of development structure, development stage and development level of ability. As far as the training objects are concerned, although this group has the same characteristics in ability literacy, there are still significant differences in the development stages and levels of specific ability literacy such as thinking ability, cognitive ability and creative ability in individual ability composition. Secondly, temperament is an inherent trait of individuals, which is generally not affected by the motivation, purpose and content of individual activities. The differences in temperament of the training objects, that is, the differences in characteristics in the dynamic level of psychological activities and behaviors, result in the differences between their individual growth states in the training process. Thirdly, personality refers to the individual's attitude towards reality and the individual psychological characteristics in their behavior, which is an important related factor affecting individual career choice. As an outstanding college student who is determined to grow up as a young Marxist, the differences in individual character will have an important impact on their choice of the path to realize their own life value. The differences in personality of the training objects determine that the training work must adhere to teaching students in accordance with their aptitude and carry out classified training.

Individual differences are caused by the psychological mechanism of different environments acting on species (human beings) (Larsen \& Bass, 2012). If we follow the principle of teaching students in accordance with their aptitude in the training work, we must accurately grasp the subjective differences of the training objects. This subjective difference refers to the differences in personality traits and talent qualifications of training objects based on the same potential characteristics of cognitive elements and affective elements, as well as the differences in professional background, family environment and growth experience of training objects. On the other hand, grasping the principle of teaching students in accordance with their aptitude in training work is different from following the principle of teaching students in accordance with their aptitude in general education and teaching activities. Its focus is on stimulating and guaranteeing the subjective role of training objects. It 
emphasizes guiding and boosting training objects to choose their own growth paths and ways according to the differences of their characteristics. It is worth noting that following the principle of teaching students in accordance with their aptitude to promote the independent choice of training objects not only points to this growth stage of young Marxists among college students, but also points to the whole struggle process of training objects to pursue scientific truth and lofty ideals in their life.

\subsubsection{Carry Out Classified Training on the Training Objects}

Classified training is an organizational model of educational activities that embodies the principle of teaching students in accordance with their aptitude. In the training of young Marxists of college students, the classified training of training objects can effectively meet the diverse needs of the growth of training objects and the training mode. At the same time, the organizational model of classified training is also an important way to train young Marxists in professional fields.

For the growth and development of the individual, classified cultivation is an important way to explore the potential of cultivation, promote the development of personality and stimulate the initiative of the subject. It is worth noting that the training target is the outstanding college students who are receiving college education, and their ability structure and comprehensive quality have shown excellent development potential. In this growth stage, the implementation of classified training according to their potential differences will effectively further promotes the personality development and self-improvement of the trainees. First of all, classified training provides conditions for the training objects to choose the training path that adapts to their own growth and development needs according to their own wishes, needs, interests and specialties. This effectively promotes the subjective development of the training object, and makes the realization of the goal orientation of training work become the intrinsic conscious behavior pursuit of the training object. Secondly, classified training is beneficial for colleges and universities to concentrate relevant high-quality educational resources, and cultivate the competency characteristics of training objects with specific development endowments in a targeted manner, thus realizing the perfection and development of the outstanding potential of training objects to the greatest extent under the condition of limited educational resources.

We should pay attention to the following three aspects in the implementation of classified training: first, the specific mode and path of classified training should help to enhance the development potential of the training object, stimulate the subjective initiative of the training object and conform to the goal orientation of training young Marxists in professional fields; Second, classified training should be based on the differences of personality traits of the training objects, and follow the law of belief generation and the law of ability literacy cultivation; Third, we should pay attention to combining the practical work and resource advantages of professional talents training in colleges and universities, and choose the implementation path of classified training according to local conditions and time.

In practical work, the subject differences and growth needs of training objects are diverse, so when implementing the classified training mode, it is necessary to effectively integrate the characteristic differences and growth needs of training objects. Therefore, it is necessary to combine classified training with project management and apply it to the training work, so as to effectively follow the principle of teaching students in accordance with their aptitude. The application of project management in the training of young Marxists of college students refers to the effective planning, organization, coordination, control and evaluation of the whole process and each link of the training work by using systematic viewpoints and methods under the condition that the diversified development needs of the training objects are in contradiction with the limited training resources, so as to achieve the teaching objectives of the training work with high efficiency.

The teaching management mode of "project teaching team" + "sequential training" can be adopted to put the concept of combining classified training with project management into concrete training practice. This model not only strengthens and promotes the affective elements of Marxist theoretical literacy and competency, but also trains its professional competence in sequence according to its personal wishes, professional background and development potential. At the same time, the combination of classified training and project management can effectively guarantee the autonomy of the teaching and training work, and prevent the training work from becoming a simple combination of political theory lectures.

\section{Conclusions}

To train young Marxists among college students, we should follow the characteristics and growth rules of college students and adhere to the following training policies and guidelines: First, the most essential feature of young Marxists is their establishment of Marxist beliefs. Therefore, the core of the training of young Marxists among college students is to cultivate and strengthen Marxist beliefs, which must follow the objective laws of the 
formation and development of Marxist beliefs. Second, the young Marxist of college students is a developmental and constructive dynamic concept. To grow into a young Marxist of college students, there are clear preconditions of affection elements and knowing and doing elements, which determines that the training of young Marxists among college students must find out the potential differences between affection elements and knowing and doing elements on the basis of dynamic selection of training objects, and implement classified training.

\section{References}

Adam Schaff (2015). Marxism and Human Individual (p. 6). Harbin: Heilongjiang University Press.

Larsen, R., \& Bass, D. (2012). Personality Psychology (p. 229). BJ: People's Post and Telecommunications Press.

Liu, J. J. (2012). Letters of Belief (p. 83). BJ: China Youth Publishing House.

Liu, J. J. (2013). On the Basic Content and Main Structure of Marxist Belief. Ideological Education Research, 3, 37-39.

Pu, Q. P., \& Yang, C. L. (2018). The Evolution of Youth Thought in the Past 40 years of Reform and Opening up and the Experience Enlightenment of Ideological Education. Chinese Youth Studies, 4, 21.

Wan, B. (2016). Marxism and Contemporary (p. 5). HZ: Zhejiang University Press.

Wan, M. (2012). Introduction to Youth Studies (p. 38). BJ: Renmin University of China Press.

\section{Copyrights}

Copyright for this article is retained by the author(s), with first publication rights granted to the journal.

This is an open-access article distributed under the terms and conditions of the Creative Commons Attribution license (http://creativecommons.org/licenses/by/4.0/). 